\title{
The power of systems thinking in medicine
}

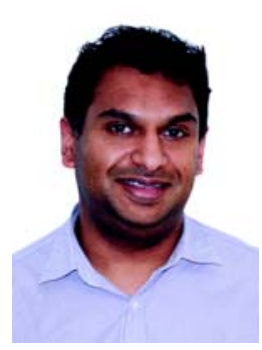

Astika Kappagoda Deputy Editor mja@mja.com.au

doi: 10.5694/mjal4.c0303 306534), it was a "system accident". The complexity of aviation systems creates conditions for small changes to interact with other system elements across technical, organisational and cultural domains to produce significant outcomes that are hard to predict and control.

All clinicians recognise the complexity of health care delivery. The system accident idea has been adopted enthusiastically by some exponents of ways to improve clinical safety, despite more recent reservations about its applicability (Health Serv Res 2006; 41: 1654-1676). Nevertheless, the assessment of clinical mishaps and adverse events requires a systems approach (not only technical, but also organisational, social and cultural).

As a starting point, registries are powerful tools for systematically detecting and monitoring clinical problems and adverse events, and for informing interventions. The study by Roxanas and colleagues of Australia and New Zealand Dialysis and Transplant Registry data (page 226) shows that the incidence of end-stage renal failure due to lithium therapy, although small, is growing. They express concern that accepted doses of lithium over a long time may result in irreversible renal impairment and end-stage disease, reinforcing the need for regular and frequent monitoring of renal function. Registry data analysis is the monitoring system providing the backbone for reducing risks for those receiving lithium therapy.

There is also a need for systems to oversee and analyse incidents in whole areas of health care. Cunningham and colleagues (page 204) point out that, in the case of chiropractic practice, there is little in place for monitoring for adverse incidents. Without such a system, proper investigation of incidents in chiropractic care cannot occur.
Significantly greater challenges exist in assessing health impacts of activities with complex influences from societal and cultural practices in the community. Clenbuterol - a $\beta 2$-adrenergic agonist with anabolic as well as bronchodilating properties, registered only for veterinary use and banned in sport - is now illicitly used in the community to aid bodybuilding and weight loss. Brett and colleagues (page 219) report a case series of clenbuterol toxicity reported to the NSW Poisons Information Centre. Details of cases suggest that it is also being used for deliberate self-harm, and that accidental ingestion has occurred. While the authors acknowledge that the study presents an incomplete picture of actual use in the community, would a deeper engagement with ideas from complexity science help in understanding the complexity of substance misuse? What additional systems need to be put in place for us to know and perhaps anticipate changing patterns of use?

No matter how complex the health problem, data registries will always have a central role in disease and health care monitoring and practice. Presently, patients often need to explicitly consent to their information being added to a registry. Olver (page 201) examines the ethical dimensions of opt-out consent, where patient data are automatically added unless consent is expressly refused. He argues that this approach is acceptable in the context of low-risk research and for improving clinical quality. Although not called a registry, the concept has been used for decades in civil aviation for mandatorily collecting flight data and operational feedback from aviation personnel. Only relatively recently have similar approaches taken hold across a broad range of health care activities.

Decades of research and application of safety assurance and improvement systems in aviation and other industries have resulted in a critical respect for the complexity of many human endeavours - the importance of monitoring outcomes and processes, understanding why and how incidents happen, and appreciating the multifaceted nature of the solutions. There are certainly limitations to mapping approaches to aviation safety to health care systems. But the analogy provides a useful starting point and source of ideas. Preventing adverse health outcomes and health care incidents matters enormously to the community. Just as a systems approach has led to civil aviation being appreciably safer, it should also be pursued by those wanting well founded solutions to complex, multidimensional problems in health. 口

\section{Many heads are better than one}

\footnotetext{
Cate Swannell

According to a business adviser working with general practitioners, "if you are in a solo practice right now in GP land, you would financially be stressing". Moving into a group practice has become a matter of survival for many GPs. Even a small shift in government funding - for example, the shift in after-hours funding from the Practice Incentives Program to

Careers follows p 232 Medicare Locals - can prove the end of a solo clinic. Annabel
}

McGilvray explores the many ways working together can improve not only the bottom line for GPs but also the experience of the patient (page C1). Professor Phyllis Butow is a medical psychologist working with cancer patients, particularly immigrants, to improve communication and, ultimately, care for those in this vulnerable group. She speaks with Cate Swannell (page C4). 
Editorials

190 MJA $200(4) \cdot 3$ March 2014 